\title{
O COTIDIANO DE NEGÓCIOS FAMILIARES EM MATOZINHOS/MG
}

\author{
THE FAMILY BUSINESS DAILY OF MATOZINHOS / MG
}

\author{
Gabriel Farias Alves Correia \\ FACE-UFMG \\ Alexandre de Pádua Carrieri \\ FACE-UFMG
}

Submissão: $11 / 09 / 2018$

Aprovação: 14/06/2019

\begin{abstract}
RESUMO
Este trabalho tem como objetivo analisar a gestão no âmbito de cinco negócios familiares localizados no bairro Bom Jesus da cidade de Matozinhos, Minas Gerais. Partindo das discussões de gestão ordinária, analisamos as estratégias e táticas cotidianas dos sujeitos por meio de suas ações. Para coleta de dados, foram realizadas onze entrevistas semiestruturadas e a análise dos resultados se deu por meio da análise linguística do discurso, sendo possível identificar dois percursos semânticos. $\mathrm{O}$ primeiro diz respeito à interconexão entre negócio e família tendo em vista que a utilização de membros familiares como próprios trabalhadores mantêm a produtividade necessária. No segundo, as estratégias e táticas cotidianas são analisadas sob a ótica da subversão das diversas leis, regras e normas. Por fim, apresentamos as considerações finais e reflexões acerca dos aspectos afetivos e informais que mantêm esses negócios e sugestões para pesquisas futuras.
\end{abstract}

Palavras-chave: Cotidiano. Gestão ordinária. Negócios Ordinários. Negócios familiares. Matozinhos.

\begin{abstract}
This work aims to analyze the management in the scope of five family businesses located in the Bom Jesus neighborhood of the city of Matozinhos, Minas Gerais. Considering the concept of ordinary management, we analyze the everyday strategies and tactics of the subjects through their actions. For data collection, eleven semi-structured interviews were carried out and the analysis of the results was done through the analysis of the discourse in the French side, being possible to identify two semantic paths. The first concerns the interconnection between business and family, since the use of family members as workers themselves maintains the necessary productivity. In the second, everyday strategies and tactics analyzed from the point of view of subversion of the various laws, rules and norm. Finally, we present the final considerations and reflections about the affective and informal aspects that maintain these businesses and suggestions for future research.
\end{abstract}

Keywords: Daily. Ordinary management. Ordinary business. Family business. Matozinhos. 


\section{INTRODUÇÃO}

O objetivo deste trabalho é analisar as táticas e estratégias cotidianas no âmbito de cinco negócios familiares localizados no bairro Bom Jesus na cidade de Matozinhos, Minas Gerais. O estudo do cotidiano em uma cidade a margem de Belo Horizonte se torna significativo ao ampliar a discussão sobre a dinâmica de pequenos negócios familiares em uma cidade que, em outros momentos, foi considerada como apenas "cidade-dormitório". Ojima et al. (2010) destaca a importância do desenvolvimento de serviços e atividades que ocorrem dentro de um modelo de urbanização onde há uma principal cidade da região, neste caso a capital Belo Horizonte, mas que mesmo pela dinâmica social emergem aspectos locais nas cidades ao redor, como as atividades que ocorrem no bairro aqui estudado. Marins e Ipiranga (2017) reiteram que o bairro é como uma separação que une, sendo um lugar que permite a interação entre o público e o privado e, por isso, seria essencial repensar os espaços dos bairros das cidades para ampliar a compreensão do organizar dos cotidianos no contexto dos Estudos Organizacionais.

O cotidiano se insere nos estudos da Administração para compreensão dos saberes não hegemônicos que podem contribuir para sistematização do conhecimento na área. Teixeira, Carrieri e Peixoto (2015) chamam atenção para as várias formas de estudo do cotidiano, contribuindo para a possibilidade de não se pensar o objeto de pesquisa de forma determinística. A diversidade possibilitada pelo estudo do cotidiano é assumida como essencial também ao estudo da gestão, e por isso, parte-se da caracterização da gestão ordinária (BARROS; CARRIERI, 2015) baseado em Certeau para evidenciar as constantes relações sociais ocorridas no cotidiano das organizações, buscando distanciamento dos saberes prescritivos difundidos pelo mainstream da gestão. Esse artigo ainda segue as considerações de Pena et al. (2016) e se justifica pela ainda incipiente produção acadêmica relacionada aos estudos do cotidiano de negócios ordinários, sobretudo, em pequenos negócios importantes na sustentação econômica brasileira. Dessa maneira, destacamos as práticas e experiências cotidianas de sujeitos comuns, desqualificados pelos saberes "oficiais" que se consideram mais "legítimos".

Destarte, Barros e Carrieri (2015) chamam atenção para a necessidade de desconstruir a existência de uma Administração unitária, permitindo múltiplas significações em relação à diversidade de negócios existentes. Além disso, são corroboradas as ideias de Quaresma Júnior, Peixoto e Carrieri (2013), Cabana e Ichikawa (2017) e Marins e Ipiranga (2017) e evidenciamos as estratégias e táticas cotidianas nas organizações como composição das diversas ações que formam o "gerir" por indivíduos silenciados, estimulando o potencial criativo que o cotidiano permite, contrapondo a criação e manutenção de grandes narrativas.

Essa contraposição também é respaldada pelo estudo dos negócios familiares. Para Lopes, Carrieri e Saraiva (2013), eles são pautados por fortes laços afetivos por não haver clara definição dos papéis profissionais, pessoais e familiares. Dessa maneira, contrapomos nesse artigo o discurso de que as dinâmicas familiares não interferem nas atividades das empresas. Ao contrário disso, ressaltamos que as continuidades dos negócios ocorrem por meio de práticas tradicionais e saberes informais que contestam a gestão de caráter universal generalista, abrindo possibilidades para gestões variadas, de diversos significados e construídas de diferentes formas (LESCURA et al., 2012).

Para tanto, após essa introdução, buscamos embasamento teórico para suportar as análises. Por isso, discorremos sobre o cotidiano na/da gestão e sobre os negócios familiares. Logo após a apresentação dos percursos metodológicos utilizados, apresentamos os resultados e discussões sobre os diversos cotidianos encontrados nos negócios do Bairro Bom Jesus. Por 
fim, realizamos nossas considerações finais sobre a pesquisa e as sugestões de trabalhos futuros.

\section{GESTÃO, COTIDIANO E O BAIRRO}

Ao pensar sobre o cotidiano, Guarinello (2004) embasa que as construções históricas relativas aos acontecimentos comuns devem ser capazes de tratar do todo e também das partes, tendo ciência que a recontagem das ações corriqueiras contribui para uma história geral que nunca conseguirá ser relatada em sua totalidade. Para Barros e Carrieri (2015) a compreensão do cotidiano, em termos de gestão, deve estar vinculada aos acontecimentos não sistematizados e que são desconsiderados pelos mecanismos formais. Carrieri, Perdigão e Aguiar (2014) complementam que conhecimentos oriundos do cotidiano podem se relacionar com conhecimentos legitimados, oportunizando novos saberes, tendo por base sujeitos tidos como desqualificados, ou seja, práticos.

Para Certeau (1994) as práticas do cotidiano são de difícil delimitação, tendo em vista que estão em dependência de um grande conjunto chamado de procedimentos. As inversões discretas se tornam objetos na percepção do autor, de tal maneira que as imposições sejam usadas para outros fins sem que sejam rejeitadas, subvertendo as diversas ações no interior do sistema. Os produtores então do conhecimento institucional e estabelecido ficariam nessa abordagem em segundo plano, evidenciando as manipulações executadas por aqueles que não as fabricam e que por elas são rejeitados.

As ações do "homem comum", muitas vezes vencido e ocultado pela história são destacadas por Ichikawa (2014, p.201) ao afirmar que "ao homem ordinário sobra um 'domínio' adaptado, pois ele carece do 'próprio', da propriedade, do espaço, mas, pela astúcia e pelas artimanhas, pelas práticas e por suas ações cotidianas subversivas no espaço do outro, ele consegue atuar". O "do outro" seria a oportunidade desse sujeito comum de praticar o cotidiano, não somente sendo rejeitado e marginalizado por ele. Com isso, é possível afirmar que "as estratégias apontam para a resistência que o estabelecimento de um lugar oferece ao gasto do tempo; as táticas apontam para uma hábil utilização do tempo, das ocasiões que apresenta e também dos jogos que introduz nas fundações de um poder" (CERTEAU, 1994, p.102).

Marins e Ipiranga (2017) asseguram a tática como "arte de manobrar" em que o fraco aproveita de situações e acontecimentos para inverter as forças, jogando com o tempo, transformando-o em ocasiões. Cabana e Ichikawa (2017) complementam que a tática possui terreno o que é do outro, possibilitando que as ações sejam tomadas dentro da considerada normalidade. Diferente disso, a estratégia procura uma visão macro que suporte as relações com uma exterioridade. Para ela, é necessária a existência de um lugar estabelecido, próprio ou uma instituição em que haja relações de dominador e dominado com normas de conduta definidas, privilegiando relações espaciais e visando o futuro. Essas duas formas de ação são as práticas que os sujeitos se apropriam da organização do espaço, que ao invés de serem pautadas numa racionalidade, são distintas a ponto de compreenderem a multiplicidade de táticas articuladas no cotidiano (MARINS; IPIRANGA, 2017).

A gestão ordinária para Barros e Carrieri (2015) não internaliza a busca de maximização da Administração com sua racionalidade instrumental, a separação entre os que produzem e empreendem nem entre o trabalho, o negócio e a família. Diferente disso, possibilita verificar como ocorre a gestão a partir dos grupos afastados dos saberes tradicionais oficiais, possibilitando observar as "intencionalidades institucionais e de grupos sociais em conduzir um acordo implícito e objetivo da não incorporação do valor humano nas 
práticas sociais" (BARROS; CARRIERI, 2015, p.159). Ao contrário da concepção positivista, Carrieri et al. (2012, p.222) constatam que os sujeitos "escapam silenciosamente dessa conformação dita racional", o que permite que o cotidiano da gestão seja reinventado a todo momento, encontrando cada sujeito o melhor modo para se fazer utilizar do espaço. É importante que a concepção não seja de uma gestão unívoca, mas de gestões plurais que permitam a fuga da perspectiva tradicional dominante e o encontro das práticas sociais daqueles que gerem o cotidiano, considerando as diversas artes de fazer (CERTEAU, 1994), que podem permitir a compreensão da realidade cotidiana. (CARRIERI et al., 2012). Portanto, a interação dos sujeitos, e desses com o ambiente, oportunizam a criação de saberes, no plural, pautado por suas práticas.

Cabana e Ichikawa (2017) afirmam ainda que as imposições em âmbito organizacional aos indivíduos ou grupos são passíveis de recusa, aceitação ou bricolagens, valendo-se de micropráticas que constroem posições de identidades temporárias. Os autores concluem que os movimentos de resistência se realizam por práticas ocultadas, não sendo interpretados como ameaças pelos dominantes, sendo o cotidiano reinventado e reinterpretado por seus praticantes. Um dos espaços que permite a constante reinvenção por seus praticantes é o bairro.

No sentido de Certeau (1994), o espaço é dinâmico, lugar praticado e que permite transformações por aqueles que por ali transitam e estão. Nesse sentido, o bairro seria um espaço, composto por múltiplas mobilidades daqueles que o compõe, diverso e que permite operações nos objetos estáveis pelas ações de sujeitos históricos. $\mathrm{O}$ autor acrescenta que a fuga de olhares totalizantes, frutos do imaginário, fazem com que se estranhe o cotidiano que não está visível, em uma percepção destorcida sobre a cidade habitada. Emerge então, dessa maneira, a necessidade de considerar as interações invisíveis dos sujeitos que habitam, vivem e produzem os espaços nessas cidades, nesses bairros.

Ademais, Certeau (1994) afirma a existência de formas utópicas de que a cidade é instaurada por meio de três operações: a) produção de espaço próprio baseado na organização racional e exclusão de tudo que comprometa essa ordem; b) estabelecimento de um nãotempo para substituir resistências únicas por métodos científicos unívocos; c) criação de um modelo universal de sujeito que é a própria cidade, por meio da construção de espaços de organizações estáveis ordenados por operações de gestão e eliminação. Isso afirma a necessidade na própria reflexão de cidades abranger discussões sobre o desaparecimento de tudo que foge do modelo estabelecido e cientificamente ordenado. No entanto, em aspectos locais como os bairros, é que as cidades se recriam graças as inversões do estabelecido, da rejeição, da astúcia, da resistência, dos desvios que não rompem com a ordem, mas que permitem que efeitos contrários sejam utilizados em favor dos praticantes. Com isso, aquilo que não é pensado por meio de uma tecnologia científica e política se reafirma enquanto ação, lugar de transformação, apropriação e reapropriação e intervenção dos sujeitos.

\section{NEGÓCIOS FAMILIARES}

O olhar para o cotidiano possibilita reconhecer a diversidade de nuances que englobam a vida organizada. As empresas familiares se constituem como objetos de problematização na medida em que se discutem vertentes associadas à natureza desse tipo de organização. Carrieri e Lopes (2012) e Borges et al. (2016) revelam uma extensa quantidade de trabalhos que buscam estudar os negócios familiares, tratando de temas conceituais, funcionais, evolutivos, financeiros, econômicos, sucessórios, estratégicos, e inovadores. 
Cançado et al. (2013) consideram que a maior parte dos trabalhos que discutem as empresas familiares buscam relacioná-las às propriedades das empresas e as influências das famílias. Além disso, os autores caracterizam as organizações familiares como aquelas que possuem dois ou mais membros de uma mesma família (ou de várias famílias) e que participam do gerenciamento dos negócios.

Apesar da existência de vários estudos sobre as organizações familiares, justificados pela dinamicidade e riqueza de possibilidades que o tema possui, a questão conceitual sobre elas ainda não faz parte de uma unanimidade na área da Administração. Dessa forma, destacam-se estudos recentes sobre diversas questões que envolvem as empresas familiares como a história e os negócios (Hjorth e Dawson, 2016), a sucessão (Teston e Filippim, 2017), as decisões financeiras (Michiels e Molly, 2017), as interações sociais nos locais onde estão instaladas (Seaman, Mcquaid e Pearson, 2017) chegando até a crítica da utilização do modelo familiar para reprodução do discurso heteronormativo (Ferry, 2017) e de gênero no contexto de sucessão familiar (Nelson e Constantinidis, 2017).

Carrieri et al. (2008) e Carrieri, Perdigão e Aguiar (2014) consideram que os negócios de família/negócios familiares constituem uma das formas da vida organizada, construindo sujeitos, relações, corpos e a visão fundida entre mundo interior e exterior aos negócios. As relações nos negócios familiares vão de encontro às diretrizes da Administração tradicional no que se refere a separação entre negócio e família. A compreensão do que acontece no interior das famílias que possuem empreendimentos se torna fundamental para compreendermos as dinâmicas dos negócios, como eles se criaram, se mantiveram e como são pensados os seus futuros. Lescura et al. (2012) destacam o respeito entre os familiares no ambiente do grupo, transmitindo comportamentos próprios do ambiente familiar para o ambiente organizacional. Carrieri, Perdigão e Saraiva (2014) reiteram a inexistência da separação entre famílias e negócios, de tal maneira que os valores da família se reafirmam no local e nos assuntos empresariais. Nesse sentido, as organizações familiares podem ser compreendidas como aquelas que:

Englobam atividades produtivas baseadas na força produtiva da família, mas que nem por isso estão dispostas sob uma hierarquia, uma estrutura, uma formalidade de relações, ou mesmo a legalização do negócio. A gestão do negócio familiar pode ser constituída de sujeitos que agem por meio de uma rede de relacionamentos informais e pessoais envolvendo, sobretudo, elementos afetivos ligados à família, podendo trabalhar sem vínculos trabalhistas legalmente formalizados (CARRIERI; PERDIGÃO; AGUIAR, 2014, p.705).

As relações subjetivas marcam os negócios familiares visto que os laços afetivos são oriundos da própria ligação familiar, o que faz com que as manifestações de poder se apresentem de modos diferenciados, tendo em vista a gama de papéis que se relacionam nos ambientes familiares (LOPES; CARRIERI; SARAIVA, 2013). Os proprietários são muitas das vezes pais, filhos, mães, tios, sobrinhos, netos que carregam todas as peculiaridades dessas relações, bem como seus conflitos e suas mazelas para o cotidiano dos negócios, interferindo diretamente em sua manutenção ou decomposição. A socialização do sujeito é realizada de tal modo que se afirme o que será aceitável e inaceitável nesse contexto, em um processo de controle e ajustamento das condutas a partir de aspectos afetivos e emocionais, pretendendo enquadrar os comportamentos nos ambientes familiares e dos negócios (LESCURA et al., 2012; LOPES; CARRIERI; SARAIVA, 2013). Cruz e Oliveira (2014, p.239) complementam que a socialização na organização familiar está diretamente relacionada com a convivência dos membros da família nas questões empresariais. Essa proximidade com os aspectos característicos dos negócios influencia também na dinâmica 
familiar, como chamam atenção os autores. Com base nisso, consideramos que a organização também pode influenciar na dinâmica familiar e não somente o contrário.

Ademais, Carrieri e Lopes (2012, p.9) reforçam o aspecto dual da família que se caracteriza tanto pela racionalidade do progresso civilizatório quanto pela afetividade inerente nas relações parentais, sendo "fundamental para a compreensão das relações nas organizações familiares". Lopes, Carrieri e Saraiva (2013) questionam se o uso das técnicas pautadas na família não seriam formas de controle e manutenção do envolvimento dos indivíduos com os negócios, as vezes até mais do que desejariam, mesmo não ocorrendo de maneira estruturada. Dessa forma, os mesmos autores ainda consideram que as relações de poder envoltas nas organizações familiares influenciam nas atividades exercidas. As questões afetivas dos negócios familiares são problematizadas no contexto capitalista, considerando que essas podem ser estratégias de sobrevivência, utilizando-se delas como instrumentos de ajustes sociais e manutenção dos negócios (LOPES; CARRIERI; SARAIVA, 2013). Além do parentesco como fonte de integração no grupo de empresas, Lescura et al. (2012) destacam a existência do parentesco como fonte de conflito, considerando interesses divergentes entre os atores e se transformando em local de disputas entre eles. Os conflitos são, muitas das vezes, utilizados como mecanismos de mediação para que não afetem os negócios, já que são fontes de subsistência.

Outros tipos de conflitos foram considerados em Cançado et al. (2013) ao analisarem a sucessão em um grupo empresarial familiar que se encontrava em processo de transição para a segunda geração. Os autores concluíram a existência de desafios relacionados ao desenvolvimento das famílias, das empresas e das propriedades, sugerindo a inclusão de estudos sobre o tema da profissionalização. Essa proposta é relevante tendo em vista a possibilidade de sucessores, desinteressados na gestão dos negócios, transferirem poderes para profissionais não pertencentes às famílias. Caso ocorra esse processo de transferência, Tabor et al. (2017) chamam a atenção para as questões que envolvem os membros não familiares em empresas familiares, afirmando que se trata de um processo com grandes desafios que podem afetar o modo como as relações ocorrem com os outros trabalhadores. Além disso, os autores reafirmam a dificuldade de administradores contratados no exercício de suas funções devido às estruturas informais que permitem, ainda assim, a influência no desenvolvimento dos negócios. Devemos considerar que para que esse estágio seja alcançado, é necessário o crescimento da empresa em outros níveis e em segmentos que permitem isso, diferente das empresas familiares estudadas nesse trabalho. Nessas, os aspectos informais fazem com que questões afetivas e os laços emocionais sejam fundamentais para sobrevivência dos sujeitos, de tal maneira, que assumimos aqui seu aspecto crucial em suas diretrizes futuras.

\section{CAMINHOS PERCORRIDOS}

O percurso metodológico da pesquisa foi pensado de modo que pudéssemos alcançar de forma adequada o objetivo proposto. Assim, buscamos analisar as táticas e estratégias cotidianas no âmbito de cinco negócios familiares localizados no bairro Bom Jesus na cidade de Matozinhos, Minas Gerais. A abordagem qualitativa permitiu o aprofundamento necessário para atingirmos a proposta da pesquisa, já que nos permite trabalhar com a realidade que não pode ser quantificada, envolvendo crenças, valores, aspirações, pensamentos e significados que levam às ações dos sujeitos (MINAYO, 2009). A pesquisa ainda é colocada pela autora como como um processo de indagação e construção da realidade, englobando pensamento e ação. 
Duarte (2002, p.140) destaca que a pesquisa engloba "um modo diferente de olhar e pensar determinada realidade a partir de uma experiência e de uma apropriação do conhecimento que são, aí sim, bastante pessoais". Tal questão embasa a pessoalidade dessa pesquisa, que não busca em nenhum momento a neutralidade e que reconhece as visões subjetivas de nós pesquisadores como necessárias para compreensão da realidade estudada.

Em um primeiro momento, partimos dos dados disponíveis no site do Instituto Brasileiro de Geografia e Estatística (IBGE) sobre as empresas atuantes na cidade de Matozinhos. Os números indicam a existência de 860 empresas, com cerca de $26 \%$ da população total ocupada recebendo a média de 2,4 salários mínimos. Em um segundo momento, recorremos a prefeitura municipal da cidade para mapearmos os setores em que as empresas se concentram. Verificamos o realce de atividades de cunho comercial, instigando nós pesquisadores a compreendermos essa especificidade. Suportados pelo órgão de administração municipal, visitamos as principais ruas comerciais dos dez principais bairros, com exceção do centro, com a finalidade de verificar quais os negócios existentes.

Dentre do universo possível, escolhemos o Bairro Bom Jesus, onde habitam residências e negócios, de classe média baixa. A escolha do bairro se pauta em duas questões: representatividade e concentração. Nele, a variedade de pequenos negócios dos outros bairros está representada. Nesse bairro, é possível encontrar negócios de produtos e serviços que variam desde bares, restaurantes, lanchonetes, distribuidoras de bebidas, distribuidoras de gás, pequenos mercados, lojas de autopeças, papelarias, cabeleireiros, salões de beleza, lojas de materiais de construção, lojas de roupas, de eletrônicos, academias até lojas de rações.

Dando prosseguimento na pesquisa, listamos todos os pequenos negócios encontrados nas principais ruas do bairro por acreditarmos, por meio de observações iniciais, que encontraríamos diversos negócios familiares. O levantamento inicial indicou vinte e cinco estabelecimentos comerciais, nos quais perguntamos, in loco, a existência de trabalhadores membros da mesma família. No final desse levantamento, chegamos ao número de treze estabelecimentos que possuíam dois ou mais membros da mesma família, coerente com o objetivo do trabalho. Neste locais, abordamos os trabalhadores explanando sobre os objetivos do trabalho e realizando o convite para participação. Obtivemos em nove o aceite e a abertura para realização da pesquisa, sendo que em cinco destes pelo menos dois membros da família aceitaram a participação, compondo nosso universo de análise. Os estabelecimentos foram: uma mercearia, existente há pelo menos dez anos; uma academia, com dois anos de funcionamento; uma papelaria, com três anos; uma sorveteria com vinte anos de existência e uma loja de ração, criada há seis anos.

Ao iniciarmos a coleta de dados, optamos pelas entrevistas semiestruturadas, tendo em vista que permite a aproximação dos pesquisadores com o universo cultural dos entrevistados (THIOLLENT, 1987). O roteiro semiestruturado possibilita, para Manzini (2004), maior flexibilidade nas falas dos sujeitos de pesquisa, diminuindo a interferência dos pesquisadores. Ademais, este tipo de roteiro é composto por perguntas elementares para auxiliar o pesquisador no processo de desenvolvimento e na compreensão por parte dos pesquisados, do objetivo da pesquisa.

Realizamos onze entrevistas no mês de setembro de 2017, no próprio local de trabalho dos entrevistados e com duração média de quarenta minutos. Abordamos temas vinculados às histórias dos entrevistados, dos negócios, o cotidiano das atividades, as dificuldades encontradas, as mudanças, a gestão, a tomada de decisão e os principais desafios na manutenção. Para preservarmos seus nomes e organizações, atribuímos aleatoriamente letras e números associados aos entrevistados e aos negócios em que estão envolvidos. Assim, ao invés de citarmos o nome do entrevistado, optamos por "entrevistado 1", "entrevistado 2", 
"entrevistado 3". Da mesma forma, ao invés de citarmos o nome do negócio, optamos por "negócio A", "negócio B", "negócio C" etc.

Para fins complementares, utilizamos em nossa coleta de dados as anotações do diário de campo, já que elas permitem, segundo Zaccarelli e Godoy (2010), registrar apontamentos relevantes para os pesquisadores no processo do trabalho de campo, envolvendo interações, gestos, reações, impressões e atividades. Além disso, foi utilizada a observação das atividades por meio da técnica de observação não participante, já que ela permite a compreensão do contexto que o pesquisador está inserido sem participar, de nenhuma forma, do contexto social do grupo pesquisado (MARIETTO, 2018).

O estudo multicasos se apresentou, na seleção, como procedimento técnico mais adequado por viabilizar o estudo de várias organizações e indivíduos de forma simultânea. Tal técnica propicia investigar situações da vida real que englobam a inexistência de delimitações precisas, de descrição de contexto em que foi empregada e da explicação de variáveis causais do fenômeno que não se utiliza experimentos (GIL, 2008; CARMO GUERRA; TEODÓSIO, 2014).

Para tratamento e análise dos dados utilizamos a Análise Linguística do Discurso (ALD) que constantemente têm sido utilizada nos Estudos Organizacionais pois, além de tornar os textos como objetos, permite destacar e interconectar fatores linguísticos e sóciohistóricos (BRANDÃO, 2002; ALVESSON; KÄRREMAN, 2011; SOUZA; CARRIERI, 2014). Ademais, esta técnica é utilizada com intuito de "respaldar análises qualitativas que busquem evidenciar processos de construção de sentido em dados contextos sociais e organizacionais" (SOUZA; CARRIERI, 2014, p. 14).

As contribuições de Faria e Linhares (1993) adaptadas por Honorato e Saraiva (2017) embasaram a realização das etapas da Análise Linguística do Discurso, tendo em vista que ela oportuniza analisar estratégias de persuasão ideológica. Por conseguinte, realizamos as análises dos dados com base nas estratégias discursivas a seguir: a) condições sociais de produção dos discursos; b) aspectos lexicais que apontam personagens, implícitos, explícitos e silenciados; c) temas e figuras explícitos ou implícitos; d) percursos semânticos estruturados a partir dos temas e figuras; e) aspectos interdiscursivos; f) aspectos refletidos e refratados.

Por fim, a partir das análises eclodiram quatro percursos semânticos: a família como braço da exploração nos negócios; as táticas e estratégias cotidianas; os diversos inícios nos/dos negócios e os conflitos na manutenção dos negócios. Para fins deste artigo, debruçamo-nos sobre os dois primeiros.

\section{APRESENTAÇÃO E DISCUSSÃO DOS RESULTADOS}

\subsection{A família como braço da exploração nos negócios}

A manutenção dos negócios envolve a família como instrumento de execução das atividades dos negócios e precarização do trabalho com base no aspecto afetivo que ela possui.

(01) Nós aqui somos três funcionários e somos famílias, então tá todo mundo dentro de casa. Mesmo que eu não quisesse passar informação para os outros dois não teria como porque a gente está sempre junto (E1).

(02) Eles fazem o que podem, a gente também procura fazer o que pode. Embora mesmo sendo, como se diz, é da família, mas mesmo assim a gente se dá bem né (E2). 
No fragmento 01 é possível identificar a tentativa de transmissão positiva da dinâmica entre trabalho e família, seguindo essa ordem de prioridade na escolha semântica. No entanto, o fragmento 02 explicita que, por mais que seja "da família", antes disso, existe uma relação entre patrão e empregado. A entrevistada se refere no plural por estar ocorrendo o processo de saída de seu outro irmão, que era sócio de sua irmã no negócio. Ela destaca que "embora mesmo sendo, como se diz, é da família mesmo assim a gente se dá bem", o que explicita a existência de conflitos silenciados entre trabalhador e patrão, diferente do tema de união destacado no fragmento 01 .

(03) Se for para passar dificuldade passa junto. [Melhor] que funcionário, por exemplo, eu penso assim, se a empresa está passando dificuldade você tem que virar o dinheiro e pagar o funcionário, tem acerto, tem os impostos, tem tudo. E ela [a esposa] como sócia, como diz, se for para ganhar, ganha, se for para perder, perde (E10).

No fragmento 03, é destacada a importância para o entrevistado de se trabalhar com a família para que, em eventuais prejuízos, não se tenha que arcar com despesas relacionadas aos pagamentos de trabalhadores. A escolha semântica em nomear a esposa como sócia, e não como empregada, faz com que ela se sinta pertencente ao negócio, mesmo sendo dele toda a tomada de decisão. O percurso semântico mostra que as dificuldades em momentos de prejuízo são amenizadas com o discurso de união no negócio. Essas contradições encontradas no fragmento encontram suporte no exposto por Lopes, Carrieri e Saraiva (2013) de que a importância da família é reforçada numa ideia de valor da união dos membros, sendo instrumento para uso do trabalho informal. Além disso, são utilizados discursos pautados na afetividade e no viés econômico, considerando que "a precarização do trabalho viabiliza, de certa forma, o negócio (CARRIERI et al., 2008, p.13). Além disso, são levantados outros benefícios pelos entrevistados no trabalho em família:

(04) Aqui mesmo ganhando pouco compensa porque eu trabalho meio horário. Se for para faltar eu posso faltar, porque eu sou a dona. Então tipo assim compensa entendeu [...] se [os filhos] ficarem doentes eu levo, aí substitui entendeu. Como é irmão não é funcionário, se fosse funcionário também complicava né, ai tinha que pagar hora extra ou dar folga depois (E5).

A relação próxima entre família e universo produtivo destacado por Lopes, Carrieri e Saraiva (2013) aparece nos discursos dos entrevistados, confirmando que as configurações ideológicas, simbólicas e morais sobrepõem à produção de bens. Com isso, a vida familiar serve de base ética e moral para que a atividade produtiva se torne central na vida dos sujeitos.

(05) Minha irmã [entrevistada 11] é melhor de mexer do que com outro funcionário [...] porque família é melhor para você mexer. Se precisar de chamar atenção você vai ter mais autoridade para chamar atenção. Uma pessoa de fora você já fíca meio sem graça (E10).

(06) Não misturo as coisas, não é que sou irmã que vou desobedecer, se eu quiser fazer o que eu quiser não! Se ele falar que tem que fazer, eu faço, se ele falar "vem abrir a loja", eu venho e abro, "fecha para mim" eu fecho. Administro dinheiro, administro ai é separado ai já não é irmã, é funcionária (E11).

O percurso semântico da família como aquela que auxilia no trabalho é explícito e é reforçado no fragmento 05 , ao dizer que a irmã está substituindo a esposa, também em papel secundário no negócio. Além disso, a intimidade proporcionada pela família é utilizada como 
instrumento para aumento de produtividade, já que seria possível "chamar atenção" sem que cause conflitos nos negócios. A reflexão desse discurso também ocorre no fragmento 06, já que o vínculo familiar é utilizado como justificativa para execução das atividades, sendo o distanciamento da condição de irmão também uma tática utilizada ao dizer que "já não é irmã, é funcionária".

Ao serem questionados sobre a relação dual de familiares no local de trabalho e de empregados nos locais familiares, as falas do entrevistados relatam ser possível a separação entre os ambientes, não interferindo nem na dinâmica de trabalho nem na dinâmica de casa.

(07) Hoje aqui é de família mesmo né, porque fica eu, meu esposo e minha filha aqui dentro [...] Eu comprei um colchão, forro colchão aqui na salinha para ela dormir, ai ela dorme depois acorda, ai eu tenho que ser mãe de manhã, ensinar ela fazer dever. E assim, eu e mais meu esposo hoje em dia a gente sabe administrar sem ter brigas, sabe. Hoje melhorou muito nosso relacionamento, a gente se dá super bem, a gente não briga e eu não misturo minha vida pessoal com [o negócio B] (E4).

No fragmento 07, apresenta-se uma contradição. O pressuposto explícito é de que casa e negócios não se misturam, com a intenção de afastar eventuais problemas familiares da produtividade que é esperada em um negócio. Quando a entrevistada escolhe em sua narrativa negar eventuais conflitos, ela está silenciando a existência dos que já houveram. Ao mesmo tempo, a entrevistada também deixa explícito que dentro do negócio os papéis de esposo e esposa, pai e mãe são mantidos, tendo a vida pessoal influência direta nas atividades, já que é necessário ter um local para descanso da filha e ajuda-la na escola, como destacado no trecho "ser mãe de manhã, ensinar ela fazer dever". Isso torna explícito que os papéis são incorporados dentro dos negócios e que negá-los seria uma tentativa de manter o negócio produtivo, refratando o próprio discurso de que a vida pessoal e negócio não se misturam.

(08) Independente se a gente tem algum problema em casa, os problemas da gente tem que ficar na casa da gente. Não pode trazer para o comércio [...] os daqui têm que ficar aqui também, você não pode levar para casa porque senão você mistura aí não dá certo (E10).

(09) Não tem conversa [na reunião de família], [negócio E] acabou, nós estamos em casa, vamos descansar, curtir a família [...]. Mas assim [eu falo] "ah ligou, você não estava lá", "ah eu vendi isso, isso, isso e dei um desconto". Quando ele vai jogar bola domingo e ele chega eu já fechei a loja. Eu pego e falo com ele, mas tirando isso nós não ficamos tocando muito no assunto não (E11).

Mesmo que nos trechos acima os entrevistados relatem a possibilidade de separação entre negócio e família, segue pertinente o questionamento de como e que maneira é feita, com quais interesses e por quais motivos. Utilizam-se de preceitos fundamentados no racionalismo positivista em que as relações de trabalho podem ser separadas dos familiares. Mas isso também apresenta uma contradição. Quando é para se destacar os aspectos positivos, a família apresenta características que possibilitam conectar questões emocionais, sentimentos de pertencimento e união que auxiliaria na manutenção dos negócios. Mas quando questionados sobre a família no local de trabalho, os entrevistados dizem conseguir realizar a separação. Ora, se é possível a separação, por que então, por diversas vezes, aparecem nos discursos dos entrevistados o aspecto positivo no trabalho com familiares? As relações nos negócios familiares são contrárias ao mainstream da Administração em relação a separação entre negócio e família, já que exclusão de emoções, sentimentos, relações sociais se torna improvável, sendo caracterizada até como fundamental para manutenção desses negócios. Assim, Carrieri, Perdigão e Aguiar (2014) embasam que as atividades produtivas conectadas à 
força produtiva da família e a ação por meio de uma rede de relacionamentos informais, envolvendo aspectos afetivos, fazem com que os negócios permaneçam como meio de subsistência para as famílias, sendo possível o trabalho sem vínculos empregatícios formalizados.

\subsection{As táticas e estratégias cotidianas}

Nos negócios analisados, apresentam-se diversas estratégias e táticas cotidianas nas diversas atividades dos sujeitos. A preferência por uma categoria específica para discuti-las foi dada para dar maior ênfase nas ações ordinárias e uma delas é a tática para conciliar as atividades de casa com o negócio.

(10) Finais de semana eu não fico aqui direto. Então [o negócio D] está aqui e por isso que a gente pôs aquela campainha, aquela campainha ali ela é sem fio. Ai quando chega alguém se eu não tiver aqui é só tocar campainha que eu atendo lá na cozinha. Lá na cozinha tem o sinal aí eu pego, venho e atendo o freguês. Depois eu volto de novo. Essa campainha é a minha companheira, ela me ajuda porque quando eu estou lá dentro fazendo as coisas. Ai se chegar alguém é só tocar, entendeu. Quando eu estou atendendo final de semana eu nem posso fazer muitas coisas lá dentro [de casa] (E8).

Tendo em vista as contribuições de Certeau (1994) e Cabana e Ichikawa (2017), o cotidiano permite jogar com que é imposto, utilizado pelo mais fraco como táticas em uma relação em que são aproveitados certos acontecimentos a procura de resultados instantâneos que permitam ganhos na vivência cotidiana. Isso é exatamente o que acontece no fragmento 10 quando a entrevistada exemplifica como ocorre a dinâmica do negócio aos finais de semana. Como precisa conciliar as atividades domésticas com as atividades do comércio, a entrevistada exemplifica o artifício do sinal sonoro para que possa realizar as duas atividades simultaneamente. No discurso ainda se utiliza da personificação no trecho "essa campainha é a minha companheira", demonstrando certo abandono e encontrando no objeto um suporte emocional. A estratégia de argumentação utilizada pela entrevistada silencia o auxílio dos filhos e do esposo nas atividades relacionadas ao lar e também de ajuda no negócio. Sem romper com o sistema que lhe é imposto, a entrevistada procura meios de alteração de sua realidade.

(11) Uai a gente conversa, fala o que tem que pôr, aí ela fala "que não sei o que isso não vai dar, agora não dá que é caro para vender”. Mas aí a gente fica falando, falando ela vai e acaba colocando né (risos) [...] a gente entra em acordo (E6).

Certeau (1994) ressalta que a tática aponta para uma habilidade de se utilizar o tempo e as ocasiões. Em uma relação de poder como a expressada no fragmento 11, o elo mais fraco se utiliza do que possui para que sua opinião seja levada em consideração. Dessa forma, são nas atividades cotidianas que se encontram modos distintos de fazer, ou seja, torna-se evidente a constante invenção e reinvenção das posições postas pelos sujeitos de maior força na relação, o que faz com que o cotidiano seja um local de constante movimento por meio de jeitos aprendidos pela experiência e adaptação de maneiras criativas e oportunistas. (CARRIERI; PERDIGÃO; AGUIAR, 2014). 
(12) Eu atendo aqui e ele me dá o dinheiro de tudo que sair, se fosse outro funcionário ele não ia fazer isso não. Ele faz isso para ajudar a gente que é família, igual minha mãe, às vezes nós revezamos (E9).

(13) Esses negócios de funcionário muita das coisas eu entro para dar um conselho, para falar que está errado. Eu entro, mas eu não me envolvo muito com a empresa, mas quando é para falar alguma coisa ele me pede opinião também, eu dou minha opinião (E8).

Nesse sentido, outra tática destacada pelos entrevistados está relacionada ao pertencimento a família para subversão de leis e regras, assim como considerou Gouvêa e Ichikawa (2015) que o cotidiano permite a subversão pelos mais fracos, criando maneiras criativas e oportunistas para ressignificação das ações. Nos trechos acima, as entrevistadas utilizam do vínculo emocional e afetivo possibilitado pela família para subverter algumas leis e normas postas socialmente nos negócios. A entrevistada 9 relata que, além de seu horário de trabalho, ela realiza o atendimento no negócio D aos domingos e que toda a renda levantada no dia é seu pagamento. A entrevistada deixa explícito que isso só é possível por ser negócio da família, o que não ocorreria se fosse um trabalhador sem vínculo familiar. O percurso semântico do negócio de família como fonte de lucro pelos sujeitos da própria família aparece implícito no discurso, já que se fosse um trabalhador qualquer isso não ocorreria. Isso se revela uma tática já que é subvertida as relações trabalhistas do negócio para ganhos do sujeito de menor poder, conforme Marins e Ipiranga (2017), transformando em ocasiões o tempo para inversão de forças.

Em outras entrevistas, que nesse caso podem ser caracterizados como dos sujeitos dominadores na caracterização de cotidiano de Certeau (1994), foram reveladas diversas estratégias sobre os negócios. Carrieri (2014) embasa que a estratégia necessita de um lugar posto, próprio ou uma instituição com a existência de relações de dominador, como no trecho:

(14) Eu tinha que montar onde que eu cresci e nasci porque o conhecimento das pessoas manda muito. [...] Eu conheço todo mundo, eu sou do bairro, moro aqui desde que eu nasci. Ai os amigos e tal, o pessoal conhece a gente, o pessoal já vai e acostuma, já tem costume de comprar aqui (E10).

No enunciado 14, relata-se que a existência do negócio no bairro foi possível a partir das relações afetivas criadas, além de seu senso de pertencimento e o conhecimento territorial. Os personagens "amigos" e "pessoal" aparecem na escolha semântica do entrevistado como fundamentais para as vendas, já que elas não seriam realizadas pela qualidade ou preço dos produtos, mas sim pelas relações sociais estabelecidas, criando um costume de compra. Dessa forma, o conhecimento da figura "bairro" aparece na narrativa como uma estratégia do enunciador para realização de suas vendas, não sendo mencionado pelo entrevistado estratégias "científicas" que envolvem o marketing, as finanças, a logística ou nenhuma das áreas que compõem o ensino do mainstream da Administração.

(15) Eu fiz até uma coisa errada na época, mas eu tinha que fazer para eu fazer o teste do [novo produto] que ninguém conhecia. [...] Peguei a coisa que ninguém conhecia e eu comecei a embalar dentro da embalagem do [produto de revenda] (E7).

O fragmento acima revela a estratégia para lançamento de um novo produto no mercado sem que precisasse investir em novas embalagens. Antes de contar sua estratégia, o entrevistado classifica a tomada de decisão no uso do lexema errada, deixando explícito que a tomada de decisão inadequada para os termos formais foi realizada de forma consciente, 
Dessa forma, o entrevistado deixa explícito que ele começou "a embalar esse [produto] dentro da embalagem do [produto de revenda]", utilizando do interdiscurso refletido do lucro a qualquer custo, propagado no sistema capitalista. $\mathrm{O}$ trecho converge com o exposto por Marins e Ipiranga (2017) de que a estratégia procura uma visão macro que suporte as relações com uma exterioridade. Quaresma Júnior, Peixoto e Carrieri (2013) afirmam que a estratégia é uma ação, que praticada pelo próprio, impele aos sujeitos formas de comportamento e maneiras de agir com a intenção de perpetuar a posição do que dita a norma, tendo em vista que mesmo que sua família o tenha reprimido pela atitude, o entrevistado 7, sujeito de maior poder continuou a realizar tal ação. A necessidade da estratégia cotidiana reprimir as forças contraventoras pode dar justificativa ao silenciamento dos outros membros familiares da tomada de decisão que poderia dar fim ao negócio, caso desse errado.

\section{CONSIDERAÇÕES FINAIS}

Nesse artigo, buscamos analisar as táticas e estratégias cotidianas no âmbito de cinco negócios familiares localizados no bairro Bom Jesus na cidade de Matozinhos, Minas Gerais. Tendo em vista que a gestão ordinária se baseia nas estratégias e táticas dos sujeitos por meio de suas ações cotidianas, utilizamos a reflexão do cotidiano proposta por Certeau (1994) para que pudéssemos analisar as diversas inversões discretas dos sujeitos. Para tal, optamos pelas entrevistas semiestruturadas em conjunto com as anotações de diário de campo e com a observação não-participante para compreendermos como elas ocorrem.

Partimos da crítica ao mainstream da Administração em que o determinismo e as prescrições para alcance de resultados ótimos são baseadas nas realidades das grandes empresas, enquanto os micro e pequenos negócios, cotidianos e comuns, permanecem marginalizados nos estudos dominantes da área. Corroboramos com Marins e Ipiranga (2017) e consideramos que as pesquisas no âmbito dos Estudos Organizacionais, que buscam evidenciar os espaços dos bairros da cidade, podem ampliar a compreensão do organizar diverso do cotidiano e da gestão. Apontamos então para o protagonismo de atividades simples e rotineiras que por mais que pareçam iguais, encontram especificidades nas maneiras de serem feitas e por isso, apropriadas em diversos sentidos. Encontramos nas empresas familiares da cidade de Matozinhos a possibilidade de contribuirmos para essa discussão.

As análises dos resultados se deram por meio da análise linguística do discurso e permitiu que discutíssemos o trabalho por meio de dois discursos semânticos verificados: "a família como braço da exploração nos negócios" e "as táticas e estratégias cotidianas". Como observamos, encontramos contradições referentes aos discursos de separação dos negócios e das famílias. Por um ponto, as separações são incentivadas quando se atendem aos interesses dos negócios, como justificativa de produtividade, ressaltando as uniões e os vínculos familiares. Por outro, quando os conflitos se tornam expostos, as emoções e os aspectos afetivos se tornam ferramentas para os membros de menor recurso nos negócios, sendo abafados pelo reforço da racionalidade que um negócio "precisa ter", afirmando assim a possibilidade do distanciamento dos aspectos familiares da gestão e a reiteração dos aspectos formais. Além disso, o sentimento de pertencimento nos negócios é estimulado por meio dos vínculos familiares, tornando a atividade produtiva elemento central nas relações dos sujeitos.

Ademais, os entrevistados relataram a crença no afastamento dos assuntos que envolvem a família e a casa, sendo possível por meio do ambiente físico. No entanto, os entrevistados nos relataram, de forma contraditória, a confusão entre esses dois espaços, ou seja, assuntos dos dois ambientes sendo tratados nos dois ambientes, sem nenhuma diferenciação. Isso corrobora o exposto por Carrieri et al. (2012, p.222) de que os sujeitos 
buscam fugir de forma invisível das conformações que se colocam como racionais, encontrando táticas astuciosas para lidar com os acontecimentos. Isso permite que o próprio cotidiano seja reinventado de forma desordenada, encontrando cada sujeito o melhor modo para se fazer utilizar dos espaços.

Por fim, destacamos a interconexão entre negócio e família em favor do sistema capitalista atual, tendo em vista que a utilização de membros familiares como próprios trabalhadores dos negócios visa manter a produtividade pautada em aspectos afetivos e emocionais, mas informais. Ainda enfatizamos que esses negócios sobrevivem, muitas das vezes, pela ausência de vínculos empregatícios formais, dependentes da mão de obra e da dinâmica familiar. No entanto, ainda que o sistema pareça impor aos sujeitos modos de viver e fazer, eles subvertem as diversas leis, regras e normas, não tendo como objetivo seu rompimento. E é exatamente por isso que o cotidiano pode ser considerado como (extra)ordinário. Como futuras pesquisas, indicamos os estudos de negócios familiares em cidades periféricas com foco nas relações cotidianas de gênero e a dinâmica patriarcal nesses espaços. 


\section{REFERÊNCIAS}

ALVESSON, M.; KÄRREMAN, D. Decolonializing discourse: Critical reflections on organizational discourse analysis. Human relations, v.64, n.9, p. 1121-1146, 2011

BARROS, A.; CARRIERI, A. P. O cotidiano e a história: construindo novos olhares na administração. Revista de Administração de Empresas, v.55, n.2, p.151-161, 2015.

BORGES, A. F.; BRITO, M. J.; LIMA, J. B.; CASTRO, C. L. C. Empreendedorismo em empresas familiares: a pesquisa atual e os desafios futuros. Revista de Administração Mackenzie, v.17, n.2, p.93-121, 2016.

BRANDÃO, H. H. N. Introdução a análise do discurso. Campinas: Editora da Unicamp, 2002.

CABANA, R. P. L.; ICHIKAWA, E. Y. As identidades fragmentadas no cotidiano da Feira do Produtor de Maringá. Organizações \& Sociedade, v. 24, n. 81, p. 285-304, 2017.

CANÇADO, V. L.; LIMA, J. B.; MUYLDER, C. F.; CASTANHEIRA, R. B. Ciclo de vida, sucessão e processo de governança em uma empresa familiar: um estudo de caso no grupo Seculus. REAd, v. 75, n. 2, 2013.

CARMO GUERRA, J. F.; TEODÓSIO, A. S. S. Pesquisa Qualitativa em Gestão Social: uma análise da produção de conhecimento em estudos de caso. Revista Gestão \& Tecnologia, v.14, n.3, p. 160-176, 2014.

CARRIERI, A. P.; LOPES, F. T. "O avô constrói, o pai usa e o neto morre de fome": histórias de família em uma organização. REGE, v. 19, n. 1, p. 3-20, 2012.

CARRIERI, A. P.; MURTA, I. B. D.; TEIXEIRA, J. C.; SOUZA, M. M. P. Estratégias e Táticas Empreendidas nas Organizações Familiares do Mercadão de Madureira (Rio de Janeiro). Revista de Administração Mackenzie, v. 13, n. 2, art. 109, p. 196-226, 2012.

CARRIERI, A. P.; PERDIGÃO, D. A.; AGUIAR, A. R. C. A gestão ordinária dos pequenos negócios: outro olhar sobre a gestão em estudos organizacionais. Revista de Administração, v.49, n.4, p.698-713, 2014.

CARRIERI, A. P.; SARAIVA, L. A. S; LIMA, G. C. O.; MARANHÃO, C. M. S. Estratégias Subversivas de Sobrevivência na "Feira Hippie" de Belo Horizonte. GESTÃO.Org - Revista Eletrônica de Gestão Organizacional, v. 6, n. 2, p. 174-192, 2008.

CERTEAU, M. A invenção do cotidiano 1: as artes do fazer. Petrópolis: Vozes, 1994.

CRUZ; A. L. A.; OLIVEIRA, J. L. Os processos de socialização dos sucessores em empresas familiares: o desafio de construir a transição multigeracional. Revista de Ciências da Administração, v.16, n. 39, p.236-249, 2014.

DUARTE, R. Pesquisa qualitativa: reflexões sobre o trabalho de campo. Cadernos de Pesquisa, n. 115, 2002. 
FERRY, N. C. It's a family business! Leadership texts as technologies of heteronormativity. Leadership, p.1-19, 2017.

FARIA, A. A. M.; LINHARES, P. T. F. S. O preço da passagem no discurso de uma empresa de ônibus. Cadernos de Pesquisa, v. 10, p. 32-38, 1993.

GIL, A. C. Métodos e técnicas de pesquisa social. São Paulo: Atlas, 2008.

GOUVÊA, J. B.; ICHIKAWA, E. Y. Ascensão e decadência de uma feira nos moldes cooperativistas: um olhar a partir do cotidiano. Gestão \& Planejamento, v. 16, n. 2, p. 185206, 2015.

GUARINELLO, N. L. História científica, história contemporânea e história cotidiana. Revista Brasileira de História, v. 24, n. 48, p.13-38, 2004.

HJORTH, D.; DAWSON, A. The burden of history in the family business organization. Organization Studies, Edmonton, v.37, n. 8, p. 1089-1111, 2016.

HONORATO, B. E. F.; SARAIVA, L. A. S. Quando a casa é a marquise, o albergue, a rua: discursos e políticas sociais para pessoas em situação de rua em belo horizonte. Administração Pública e Gestão Social, v.9, n.4, p.244-253, 2017.

ICHIKAWA, E. Y. O grupo de estudos organizacionais: uma história entre outras histórias. Farol - Revista de Estudos Organizacionais e Sociedade, n.1, p. 190-211, 2014.

INSTITUTO BRASILEIRO DE GEOGRAFIA E ESTATÍSTICA. Disponível em: $<$ https://cidades.ibge.gov.br/painel/historico.php?codmun=314110>. Acesso às 21:57 em 23 de março de 2018.

LESCURA, C.; BRITO, M. J.; BORGES, A. F.; CAPELLE, M. C. A. Representações sociais sobre as relações de parentesco: estudo de caso em um grupo empresarial familiar. Revista de Administração Contemporânea, v. 16, n. 1, art. 6, pp. 98-117, 2012.

LOPES, F. T.; CARRIERI, A. P.; SARAIVA, L. A. S. Relações entre poder e subjetividade em uma organização familiar. Organizações \& Sociedade, v.20, n.65, p. 225-238, 2013.

MANZINI, E. J. Entrevista semiestruturada: análise de objetivos e de roteiros. In: Seminário Internacional Sobre Pesquisa e Estudos Qualitativos, 2, 2004, Bauru. A pesquisa qualitativa em debate. Anais... Bauru: USC, 2004.

MARIETTO, M. Observação participante e não participante: contextualização teórica e sugestão de roteiro para aplicação dos métodos. Iberoamerican Journal Of Strategic Management, v. 17, n.4, p. 5-18, 2018.

MARINS, S. R.; IPIRANGA, A. S. R. O organizar ampliado de práticas cotidianas nos bairros da cidade. Farol - Revista de Estudos Organizacionais e Sociedade, v.4, n.9, p. 148-204, 2017. 
MICHIELS, A.; MOLLY, V. Financing decisions in family businesses: a review and suggestions for developing the field. Family Business Review, v.30, n.4, p. 369-399, 2017.

MINAYO, C. S. O desafio da pesquisa social. In: MINAYO, C. S. Pesquisa Social: teoria, método e criatividade. Petropólis: Vozes, 2009.

NELSON, T.; CONSTANTINIDIS, C. Sex and gender in family business succession research: a review and forward agenda from a social construction perspective. Family Business Review, p.1-23, 2017.

OJIMA, R.; MARANDOLA JR, E.; PEREIRA, R. H. M.; SILVA, R. B. O estigma de morar longe da cidade: repensando o consenso sobre as "cidades-dormitório" no Brasil. Caderno Metrópole, v.12, n.24, p.395-415, 2010.

PENA, F. G.; MARTINS, T. S.; OLIVEIRA, L. L.; CARRIERI, A. P. O polo da moda em Belo Horizonte: uma análise histórica do Barro Preto. Revista de Administração FACES Journal, v. 15, n. 4, p. 8-26, 2016.

QUARESMA JÚNIOR, E. A.; PEIXOTO, D. L.; CARRIERI, A. P. A cristalização de uma microrrevolução francesa: o caso das cooperativas de Salinas-MG. Revista de Administração Mackenzie, v. 14, n.6, p. 162-183, 2013.

SEAMAN, C.; MCQUAID, R.; PEARSON, M. Social networking in family businesses in a local economy. Local Economy, v.32, n. 5, p.451-466, 2017.

SOUZA, M. M. P.; CARRIERI, A. P. A análise do discurso em estudos organizacionais. In: SOUZA, E. M. Metodologias e analíticas qualitativas em pesquisa organizacional: uma abordagem teórico-conceitual. Vitória: EDUFES, 2014. p. 13-38.

TABOR, W.; CHRISMAN, J. J.; MADISON, K.; VARDAMAN, J. M. Nonfamily members in family firms: a review and future research agenda. Family Bussines Review, v.31, n. 1, p.54-79, 2017.

TEIXEIRA, J. C.; CARRIERI, A. P.; PEIXOTO, T. C. O cotidiano da cidade de Belo Horizonte na revista Veja BH: a classe média alta, a cidade poderosa e os dilemas do planejado versus o vivido. Revista Gestão e Conexões, v. 4, n.2, p.8-40, 2015.

TESTON, S. F.; FILIPPIM, E. S. Perspectivas e desafios da preparação de sucessores para empresas familiares. Revista de Administração Contemporânea, v.20, n.5, p. 524-545, 2016.

THIOLLENT, M. J. M. Crítica metodológica, investigação social e enquete operária. São Paulo: Polis, 1987.

ZACCARELLI, L. M.; GODOY, A. S. Perspectivas do uso de diários nas pesquisas em organizações. Cadernos Ebape.BR, v.8, p. 550-563, 2010. 